\title{
DIETÉTICA E ESTÉTICA NO ROMANTISMO PORTUGUÊS: SUBSÍDIOS PARA UMA LEITURA FEMINISTA
}

\author{
Henrique Marques Samyn \\ (Universidade do Estado do Rio de Janeiro)
}

\section{RESUMO}

O artigo visa a apresentar considerações decorrentes de uma pesquisa preliminar acerca da estética da magreza na literatura romântica portuguesa. Desde uma perspectiva feminista, defende-se que o ideal romântico da mulher magra e pálida está profundamente relacionado à preservação de estruturas patriarcais na sociedade europeia pós-revolucionária, o que teve um impacto efetivo na dieta das mulheres ao longo do século XIX, inclusive em Portugal.

PALAVRAS-CHAVE: Romantismo, mulheres, dieta.

\begin{abstract}
The article aims to present findings of a preliminary research on the aesthetics of thinness in Portuguese romantic literature. Working from a feminist framework, it is argued that the romantic ideal of a thin, pale woman is deeply related to the preservation of patriarchal structures in post-revolutionary European society, which had a real impact on women's diet in the nineteenth century, including in Portugal.
\end{abstract}

KEYWORDS: Romanticism, women, diet. 


\section{INTRODUÇÃO: LER A ESTÉTICA CORPORAL À LUZ DO FE- MINISMO}

Este artigo pretende constituir um primeiro passo em direção a uma investigação futura, cuja indagação fulcral pode assim ser formulada: de que modo pode ser compreendida a estética da magreza na literatura produzida em Portugal durante o período romântico - tema que, vale ressaltar, pode ser investigado tanto a partir da produção literária que denota as marcas do romantismo, quanto a partir daqueles textos que, contemporâneos ou posteriores, visam efetuar uma crítica explícita dos valores românticos -, especificamente desde uma perspectiva feminista? Nesta seção introdutória, buscarei apresentar, em termos gerais, alguns dos parâmetros subjacentes à concepção da referida pesquisa; posteriormente, ao longo das demais seções do artigo, ensaiarei investidas preliminares em textos literários que deverão constituir parte do corpus a ser nela investigado.

No que tange à abordagem viabilizadora da investigação de que aqui se ensaia um primeiro passo, julgo pertinente evocar o título da importante obra de Susie Orbach (1978): "gordura é uma questão feminista". Publicado no fim dos anos 70, o livro de Orbach estava em profundo diálogo com perspectivas características daquela etapa histórica de desenvolvimento do feminismo; começava então a emergir o aparato reflexivo de uma perspectiva radical, cuja elaboração teórica, orientada para a raiz da opressão sexista, dispensava o comprometimento com agendas políticas consolidadas, baseando-se na experiência atual das mulheres, e rompia com concepções tradicionais de poder, concebendo a esfera pessoal e privada como sujeitas à dominação patriarcal (cf. BRYSON, 2003, p 163). Com efeito, ao analisar as diferentes formas como a gordura é investida de significados no âmbito da cultura, Orbach foi efetivamente capaz de demonstrar como "ser gorda", na sociedade contemporânea, constitui "uma tentativa de romper com os estereótipos sexuais da sociedade"; e como o próprio ato de engordar constitui "um desafio dirigido, consciente ou inconscientemente, à estereotipagem de papéis sexuais e a vivências de feminilidade culturalmente definidas" (ORBACH, 1978, p. 21).

Por conseguinte, reconhecer que "gordura é uma questão feminista" implica problematizar o modo como um conjunto de dispositivos de controle incide sobre o sujeito feminino, atuando diretamente sobre sua relação com o próprio corpo. Em outras palavras: para uma mulher, ser gorda ou ser magra - evidentemente, consoante critérios que variam de um contexto cultural, geográfico e histórico para o outro - implica ocupar um espaço político determinado; trata-se de uma condição imediatamente vinculada à elaboração, de modo consciente ou inconsciente, de estratégias para lidar com estruturas de poder. Pode-se, desse modo, indagar pelo sentido mesmo da magreza e do sobrepeso em um contexto cultural específico, questionando de que modo essas particularidades corporais e o que com elas está relacionado - como, quando, o que se come, o que significa recusar a comida, ou alimentar-se em excesso? - se inscrevem na trama de significados estabelecidos no âmbito social. 
A perspectiva adotada por Orbach se reflete em uma problematização mais ampla, desde um enfoque feminista, que vem sendo bastante explorada em tempos recentes. No que diz respeito à análise crítica da estética corporal como dispositivo de poder sexista na sociedade contemporânea, é bastante conhecida a obra em que a crítica cultural estadunidense Naomi Wolf analisa o "mito da beleza" (2002; a primeira edição é de 1991, havendo tradução brasileira datada já do ano seguinte). No referido livro, Wolf se dispunha a investigar de que modo as reações antifeministas faziam das imagens de beleza femininas uma arma política contra a emancipação das mulheres, ancorando-se em uma extensa tradição patriarcal a fim de preencher o espaço deixado por mecanismos de controle que se haviam enfraquecido devido às conquistas feministas - como os mitos em torno da domesticidade e da passividade, por exemplo (2002, p. 10-12). Não obstante, o uso político de ideais de beleza como instrumento de poder sexista não é um fenômeno circunscrito à contemporaneidade; com efeito, operam, como condição de possibilidade para que isso ocorra, estruturas de pensamento que provêm de épocas bastante anteriores.

Como vem destacando Susan Bordo, é constante no pensamento ocidental, para além das variações históricas, a construção do corpo como algo periférico à verdadeira subjetividade - seja ela concebida como mente, espírito, vontade, alma ou qualquer elemento similar -, sendo essa mesmo obstada de realizar-se pela existência daquele; por outro lado, esse esquema dualista é generificado, de tal modo que convencionalmente à mulher é associado o corpo, ao passo que a subjetividade verdadeira é associada ao homem. "Se, qualquer que seja o conteúdo histórico específico da dualidade, o corpo é o termo negativo, e se a mulher é o corpo, então mulheres são aquela negatividade", sintetiza a mencionada filósofa; desse modo, ela é constantemente associada à "distração do conhecimento, sedução para longe de Deus, capitulação ao desejo sexual, violência ou agressão, fracasso da vontade, mesmo a morte" (BORDO, 2003, p. 5; tradução minha). A associação da mulher ao corpo deriva, por conseguinte, de um lastro histórico que lhe serve como fundamento e simultaneamente viabiliza a recorrente atualização de mecanismos de controle inscritos na dinâmica patriarcal.

Insights como os de Orbach, Wolf e Bordo vêm alimentando, nas últimas décadas, diversas investigações acerca do substrato político das representações de corpos femininos, não se excluindo aquelas produzidas ao longo do período romântico. Será esse o tema da seção seguinte deste artigo.

\section{FRAGILIDADE ROMÂNTICA E APARÊNCIA FEMININA}

A historiografia mais recente - sobretudo a produção historiográfica de orientação feminista - vem demonstrando que, a despeito do discurso pretensamente universalizante sustentado por seus principais agentes, a Revolução Francesa pouco fez no que diz respeito à emancipação feminina; sob certos aspectos, chegou mesmo a constituir um retrocesso. 
Pode-se evocar, apenas à guisa de ilustração, o que sobre esse assunto afirmou a historiadora Catherine Marand-Fouquet - ela mesma uma veemente defensora da panteonização de Olympe de Gouges, a mais célebre das revolucionárias -, segundo a qual as ações femininas ou feministas durante este período não renderam quaisquer frutos no que tange à futura emancipação; não haveria, com efeito, qualquer continuidade entre elas e a luta feminista contemporânea. Para Marand-Fouquet, isso em parte se explica pelas dificuldades econômicas e pela situação de guerra, o que acabou por ensejar uma luta pela sobrevivência - algo agravado pelos "jogos masculinos" que excluíam as mulheres das assembleias políticas (MARAND-FOUQUET, 1993, p. 303-304). Importa, contudo, não desprezar o peso das forças políticas de uma Revolução que, em diversos sentidos, não hesitou em aceitar compromissos com a tradição, o que ensejaria uma recusa à mulher do reconhecimento como igual (MICHAUD, 1999, p. 91). Como apartar a tradição política ocidental das estruturas patriarcais que a ela sempre estiveram associadas?

Com efeito, no período que se seguiu à Revolução teria lugar um vigoroso backlash no que tange ao processo de emancipação das mulheres, não restrito ao contexto político e cultural francês. No âmbito da pretendida reconstrução da sociedade, seria reservado aos homens o papel de protagonistas que historicamente sempre lhes coubera, desde referenciais sexistas; naquele momento histórico, isso seria viabilizado não só pelo afastamento das mulheres dos círculos nos quais tinham lugar as discussões e as tomadas de decisão políticas, mas também pelo estabelecimento de uma ordem social que assegurava lugares de atuação diferenciados para os gêneros.

O confinamento das mulheres ao espaço doméstico correspondia ao ideário do regime napoleônico, que as vinculava ao destino de serem esposas e mães; educadores da época ecoavam o discurso do soberano, segundo o qual o objetivo de todas as meninas que vinham ao mundo era o casamento - o que, aliás, justificava que lhes fosse dispensada uma educação restrita às boas maneiras, uma vez que não lhes cabia participar da vida pública (BURTON, 2007, p. 31-33). Considerado um triunfo do estado revolucionário sobre a igreja, o Código Civil napoleônico constituía, nas palavras de Susan Bell e Karen Offen (1983, p. 37), uma síntese de elementos iluministas e das convicções patriarcais do próprio Napoleão - para quem as mulheres estavam destinadas a serem propriedades dos homens, obedecendo-lhes e fornecendo-lhes uma prole. Reforçava-se, assim, a tradicional dicotomia, própria do patriarcado, que concebia as mulheres como sujeitos privados, não cidadãs públicas, cabendo à sociedade prepará-las para desempenharem o seu papel na esfera doméstica (GREEN, 2000, p. 412).

Não é difícil perceber a estreita relação que há entre essa ordem social e política e a coeva cultura romântica, em particular quando se cotejam os modelos hegemônicos de masculinidade e de feminilidade então vigentes, que não deixam de comparecer também na literatura; assim, ao homem tipicamente dotado de força, coragem e impetuosidade - qualida- 
des que, evidentemente, capacitavam-no para agir nos espaços exteriores e públicos -, correspondia a mulher tipicamente frágil, sentimental e passiva - portanto, "naturalmente" destinada a habitar os espaços interiores e domésticos. Por outro lado, o modelo do gênero feminino hegemônico vigente durante o romantismo determinaria a conduta das mulheres no que tange à alimentação, sobretudo na medida em que a aparência era socialmente percebida como uma expressão das qualidades intrínsecas à pessoa. Analisando o que denominou "cultura vitoriana da anorexia", Anna Krugovoy Silver (2002, p. 27) rastreou um conjunto de características básicas, dentre as quais podemos destacar: a validação do corpo esguio como ideal físico de beleza; a crença de que a mulher perfeita é aquela que submete seus apetites físicos - tanto sua sexualidade quanto o seu desejo por comida - à sua vontade, sendo mais espiritual e menos carnal que os homens; e a crença de que o corpo esguio corporifica essas capacidades de autocontrole e espiritualidade. Por conseguinte, à espiritualização da mulher correspondia uma estrutura de valores que a confinava ao espaço doméstico, concebido como seu lugar por excelência; por outro lado, a literatura romântica cumpriria o papel de reforçar, no imaginário coletivo, esse modelo de mulher cujas fragilidade e delicadeza se manifestariam fisicamente através da aparência - uma aparência que, evidentemente, devia ser administrada pela própria mulher, por intermédio do recurso a um regime estrito. A cultura romântica portuguesa não deixaria de desenvolver uma "estética da magreza”, projetando socialmente um modelo de mulher cuja aparência física possa expressar as desejáveis fragilidade e espiritualidade femininas - isso a despeito de um imaginário tradicional que rezava que "a adem, a mulher, e a cabra, he má cousa sendo magra" (ROLLAND, 1841, p. 3).

Em 1841, João de Andrade Corvo começou a publicar em $O$ mosaico: jornal d'instrucção e recreio, periódico do qual era colaborador assíduo, um "romance original" intitulado Pedro. O título da narrativa remetia ao seu protagonista: um poeta que, após o terremoto de 1755, ao procurar sua irmã entre as ruínas, conhece Maria, jovem por quem prontamente se apaixona - que, contudo, não apenas está prometida a outro homem, Aphonso, como é também amada por outro jovem, Eduardo; há aí, previsivelmente, todos os elementos para uma história de amores arrebatados e episódios sangrentos, que se estende por quatro edições do periódico. Em seu nonagésimo quarto número, $O$ mosaico publicava o quinto capítulo de Pedro; o trecho se abre com uma descrição de Maria ainda mais encantadora devido à cada vez mais patente fragilidade, exacerbada pelo sofrimento:

Sentada n’um terrasso á borda do Téjo, uma joven palida e magra, mas fermosa e meiga como a imagem da saudade; vestida de negro, e com os cabellos negros, como os vestidos, cahidos em anneis sobre o collo alvissimo, vagueando com os olhos melancolicos, e escoando-lhe polo rosto uma lagrima, e sorrindo tristemente, contemplava, ora as ondas mansinhas que vinham beijar a praia, suspirando brandamente, ora as nuvens collossaes que se accumulavam no horisonte, $\mathrm{e}$ 
que reflectindo os ultimos clarões do Sol, semelhavam montanhas de fogo, ora algum pequeno barco que escorregava rapido sobre as aguas, deixando assignalada a estrada que havia seguido. (CORVO, 1841, p. 59)

"Pálida e magra, mas formosa e meiga": aos olhos dos enamorados Pedro e Eduardo, a adversativa soaria improcedente - e com eles certamente concordariam as leitoras e leitores afeitos à estética romântica; não por acaso, é neste momento que os dois jovens confessam à donzela uma paixão à qual já lhes é impossível renunciar. Com efeito, o aspecto enfermiço de Maria, transparente em suas magreza e palidez, é o que faz dela irresistível aos olhos masculinos, que nela enxergam a concretização do ideal de espiritualidade. "Adorar-te-hei de joelhos como um Anjo purissimo, em que se concentram todas as perfeições", afirma Eduardo; a mesma imagem é evocada por Pedro, para quem a amada semelha um "anjo de Deus" (CORVO, 1841, p. 60-61). Cabe, no entanto, ressaltar que Maria não constituía um exemplar isolado no corpus literário romântico português - em que são frequentes descrições de mulheres cuja beleza, textualmente registrada, se adequa aos parâmetros estéticos abordados na seção anterior; evoquemos alguns exemplos, deliberadamente colhidos de obras publicadas ao longo das duas décadas seguintes.

Ao descrever Eugênia, em O último amor - jovem cuja "belleza offerecia uma tal distincção e originalidade, que desde logo convidava ao enthusiasmo as naturezas mais positivas" -, Lopes de Mendonça não deixaria de ressaltar como "o vestido branco, que trazia, realçava a pallidez do seu rosto, e desenhava suavemente o aerio, o fragil d'aquelle corpo, levemente pendido, como os lyrios sobre a corrente, e que um sopro bastaria a desvanecer da terra" (MENDONÇA, 1849, p. 513). Em 1857, publicava-se o volume Cenas da Foz, de Camilo Castelo Branco; obra de que consta Dinheiro, narrativa que trata do episódio amoroso envolvendo Leocádia/ Felismina e Vasco. Já o modo como aquela surge nos primeiros capítulos da novela explicita em que medida corresponde a outra ocorrência do modelo romântico de feminilidade: anunciada pela voz que ao narrador evoca "o anjo que segredava ás estrellas as magoas do seu exilio", "o espirito aerio [...] a descer das regiões ethereas para encher a terra das harmonias santas que foram a linguagem humana antes da queda da primeira mulher", posteriormente é descrita como sendo "[p]allida, muito pallida, sem mancha de rubôr, sem beta d'outra luz que não seja a que os brandões mortuarios reflectem no crepe da eça", o que enseja a ponderação: "Devia ser muito delicada a breve construcção ossea d'aquella mulher, que no melindroso das fórmas exteriores, mostrava ser apenas o involucro material d' um grande espirito"; ademais, a palidez e a magreza das faces de Leocádia/Felismina, concedendo visibilidade corporal à espiritualidade interior, afastam-na de toda a "sensualidade grosseira" (CASTELO BRANCO, 1860, p. 117-123).

Quatro anos mais tarde, A Grinalda - periódico portuense dedicado à publicação de poesias inéditas - estamparia nas páginas de seu 
quinto volume um poema composto em homenagem a Emília das Neves, para não poucos a maior atriz portuguesa do oitocentos. Atriz formada por Émile Doux, grande mestre dos atores românticos portugueses, a "Linda Emília" se tornara uma figura central no cenário cultural desde que estreara, aos dezoito anos, dando vida à Infanta D. Beatriz de Um auto de Gil Vicente (1838), peça fundadora da dramaturgia romântica portuguesa, concebida por Almeida Garrett. A composição de Faustino Xavier de Novaes - originalmente publicada sem assinatura, embora de uma nota no mesmo volume já contasse a atribuição, e republicada nas Poesias posthumas (1870) já com o título A Emilia das Neves - não poupava imagens para cantar, ao longo de quinze páginas, as qualidades da atriz e os arroubos que causava no público. Destacando os mais impressionantes aspectos da "grande, altiva e majestosa" atriz, o poema deixa transparecer a que ponto a atriz figurava as qualidades estéticas românticas, aos olhos de seus contemporâneos; de fato, o poeta não deixaria de mencionar, além da palidez das faces e da "voz suavíssima", também a "das carnes, magreza extrema", assim remetendo à perfeição com que Emília lograva encarnar aquele modelo ideal de mulher (NOVAES, 1864, p. 110) - o que era, não obstante, facilitado por sua compleição: não por acaso, um texto poucos anos antes publicado no Archivo Pittoresco cuidava de destacar a "esbelta e gentil figura" da atriz (1860, p. 356).

\section{DIETÉTICA ROMÂNTICA E MODELOS DE FEMINILIDADE}

O ideal de beleza figurado nestas e noutras páginas literárias inevitavelmente seria elevado a uma esfera normativa, configurando um ideal insistentemente procurado pelas jovens portuguesas. Considerando-se o contexto português, é crucial observar que o romantismo constitui um momento em que a burguesia produz uma cultura para si mesma, no âmbito de um processo histórico que, nas palavras de Alberto Ferreira, (1971, p. 41), enseja um "reinado da burguesia como potência"; não obstante, é impossível dissociá-lo daquele movimento mais amplo em que, ao longo do século XIX, aqueles que ambicionavam uma posição como protagonistas de uma nova ordem social pós-revolucionária logravam capitanear o paralelo e necessário processo de renovação cultural. De fato, um grosseiro esboço de análise do modo como os modelos de masculinidade e de feminilidade comparecem na anteriormente mencionada narrativa de João de Andrade Corvo já nos pode fornecer alguns indícios sobre o que expressavam no que tange às expectativas sociais. Se a palidez não tinge apenas as faces de Maria, sendo visível também nas feições masculinas, importa observar que materializa formas de conduta opostas: no caso dos homens, concretiza o desajuste às convenções sociais, a postura de revolta levada ao extremo que reflete, mesmo que de modo eventualmente distorcido - quando ultrapassa os limites da legalidade, chegando ao assassinato -, a disposição revolucionária daqueles homens que, diante das ruínas da sociedade antiga, tornavam-se os criadores de novos valores; a palidez feminina, por sua 
vez, representa uma condição essencialmente espiritual, associada tanto à delicadeza quanto a uma morbidez imobilizante, algo igualmente compreensível no contexto das novas estruturas sociais.

O retrocesso que uma historiadora como Catherine Marand-Fouquet percebe no que diz respeito à condição feminina, derivado já do processo revolucionário de fins do século XVIII, assume contornos definidos ao longo das décadas seguintes, a partir da instituição na Europa - em Portugal, inclusive - dos diversos códigos civis inspirados naquele concebido à sombra de Napoleão. Simultaneamente herdeiro da revolução e uma reação contra ela, a ambiguidade do código napoleônico demonstra sua dimensão reacionária sobretudo no que tange à ordem familiar, uma vez que reassegurava a autoridade patriarcal dos pais sobre os filhos e dos maridos sobre as esposas (DESAN, 2013, p. 480). Também no contexto português, tudo isso vinha adequar-se a estruturas patriarcais já vigentes, perpetuando o ideário que já enfatizava nas mulheres a dependência e a necessidade de proteção.

Ressalta Irene Vaquinhas que "o próprio romantismo ajudou a forjar este tipo feminino, ao construir uma imagem de mulher simultaneamente idealizada e insignificante"; ganhavam relevo, por conseguinte, a imagem da "mulher frágil", que tinha na vulnerabilidade uma característica fundamental, e a "mulher espartilhada em termos físicos ou morais", à qual era oferecido um resguardo patriarcal que a mantinha em posição "virginal e ignorante". Sua idealização pelos poetas concorria para incutir a crença de que a mulher tanto mais agradaria quanto fosse capaz de afastar sua dimensão "terrestre", "revestindo a aparência de um ser evanescente"; importava assumir um aspecto etéreo, um tom de pele pálido, bem como estilizar a silhueta, para isso recorrendo a "dietas draconianas" que incluíam a ingestão de vinagre (VAQUINHAS, 2000, p. 24-25).

Não apenas em Portugal as jovens buscavam adequar-se aos parâmetros estéticos românticos por meio da privação alimentar e do recurso ao vinagre. Em seu estudo sobre a tuberculose e a imaginação literária vitoriana, Katherine Byrne observa que, no contexto britânico, Byron já recorrera à dieta para assumir um aspecto "espiritualizado", emulando a aparência de Keats e Shelley; mas que, posteriormente, o hábito foi adotado predominantemente pelas mulheres, que bebiam vinagre para adquirir um aspecto etéreo e enfermiço, o que favorecia a sua imagem como seres apartados das preocupações mundanas, dedicados a atuarem como "anjos do lar”, guardiões espirituais devotados a seus maridos (BYRNE, 2011, p. 94-95). Em Portugal, já em 1822 os Estatutos da Sociedade do Giro dos Vinagres do Alto Douro registravam o entusiasmo dos produtores diante das notícias de uma nova moda, no Porto, do uso de certo vinagre, apelidado "filáucia", que servia "para descorar Senhoras"; concluíam os portugueses que ter daquele vinagre lhes daria crédito, visto que "elle não só descorava, mas que tambem tinha a virtude de emmagrecer quem o usava” (ESTATUTOS, 1822, p. 48). 
Textos que circulavam no Portugal oitocentista oferecem registros não apenas sobre os efeitos do vinagre, mas também sobre o seu uso pelas mulheres portuguesas da época. O Diccionario de medicina popular, assinado pelo renomado Pedro Luiz Napoleão Chernoviz - polonês que se radicara na França por participar do levante contra o domínio russo, e que viera tentar a sorte no Brasil em 1840, rapidamente se tornando membro titular da Academia Imperial de Medicina -, obra que alcançaria fama não apenas no espaço luso-brasileiro, mas também na Espanha e na América Latina, afirma que "tomado puro em jejum, durante certo tempo, póde produzir um emmagrecimento rapido e affecções mais graves"; Chernoviz ainda transcreve o relato sobre uma moça "que, temendo chegar á corpulencia de sua mãi, tomava, por conselho de um curandeiro, um calix de vinagre em jejum, todas as manhãas; o emmagrecimento foi prompto" - e, certamente à guisa de advertência, acrescenta que "sendo o mesmo meio continuado, o marasmo fez tantos progressos, que a moça succumbio" (CHERNOVIZ, 1851, p. 583). Já o tratado toxicológico de José Ferreira de Macedo Pinto, publicado em 1860, registra serem "bastante frequentes os casos em que mulheres tomam grandes dóses de vinagre, umas chloroticas e tendo perversão do gôsto; e outras com o fim de emagrecer", em nota acrescentando considerar "um pouco frequente este prejuizo no nosso povo" e adicionando um depoimento pessoal: "no exercicio da clinica tivemos occasião de observar dous casos de graves padecimentos gastricos, occasionados pelo abuso de beber grandes porções de vinagre" (PINTO, 1860, p. 649). Bebia-se, portanto, vinagre em Portugal - quando não se recorria puramente ao jejum; e quem o fazia com maior frequência, senão as mulheres desejosas de assumirem um "aspecto romântico"?

Uma das obras camilianas de cariz mais nitidamente moralizante, Coração, cabeça e estômago, originalmente publicada em 1862, pode ser lida como um registro, em clave literária, dessas práticas sociais. Silvestre da Silva, protagonista da obra - e alter ego de Camilo, como ressalta Alexandre Cabral (1985, p. 63) -, testemunhou o modo radical como as jovens portuenses perseguiram esse ideal estético. Contaminadas pelo "bafo pestilencial do romance", impregnadas pela cultura romântica, essas meninas "invejavam a pallidez das pallidas, e a espiritualidade das magras"; para se tornarem como elas, estavam dispostas a tudo: "Tal menina houve que bebeu vinagre com pó de telha"; "muitas, á força de jejuns, desmedravam a olhos vistos". E tudo isso para emular aquelas mulheres cuja transformação física, por vezes, transparecia nas próprias narrativas romanescas: cita-se na obra o caso da personagem que, no primeiro capítulo, aparecia "bem fornida de carnes, e rosada e espanejada como as bellas dos campos", para no terceiro surgir "com olheiras a relevar o cavado do rosto, com a cintura a desarticular-se dos seus engonços, com as mãos translucidas de magreza, os braços em osso nú e os olhos apagados nas orbitas, orvalhadas de lagrimas" (CASTELO BRANCO, 1864, p. 122-125). Poderia o mesmo escritor que participara da construção de uma imagem de mulher que sustentava essas práticas - como vimos anteriormente, ao abordarmos a Leocádia/ Felismina presente em Cenas da Foz - adotar, em outro texto, uma posição 
crítica perante elas? Decerto sim, se considerarmos a posição de Camilo como "autor que constrói a respectiva obra na acumulação de títulos de circunstância”, no dizer de Abel Barros Baptista (2012, p. 23).

Por outro lado, Camilo Castelo Branco está também relacionado a um interessante registro acerca do interesse masculino pelas mulheres que se adequavam a esse modelo. Os Serões litterarios de José Bento d'Araujo Assis, publicados em 1869, foram dedicados ao escritor de Ceide - que comparece como prefaciador da obra graças a uma carta, transcrita no volume, em que aceita a dedicatória, tecendo elogios ao autor. Num dos textos compilados no livro, Pela bocca morre o peixe, Assis relata o episódio envolvendo um homem que, repudiando a princípio a ideia de casar-se alegando como razão principal a "decadência" da beleza feminina ao longo dos anos -, acaba por ceder, meramente interessado na fortuna a ser herdada pela esposa. As feições da mulher considerada bela, como descritas no texto, remetem uma vez mais à busca da magreza pelas jovens portuguesas: o que pode atrair o homem senão uma menina "magra, pallida, de olheiras pronunciadas", que ostente uma "cintura de vesta, capaz de cingir-se com dois dedos"? Contudo, ao longo do tempo, é inevitável a decadência - "e tu que gostaste de tua mulher por ser pallida, vaes-lhe vendo as faces rosadas"; ou, o que é decerto pior: "e tu que gostavas d'ella por possuir a mais delicada cintura do universo, já não pódes cingir a de tua mulher senão com ambos os braços" (1869, p. 292-293). É, portanto, ao deixar de ser magra que a mulher se torna desinteressante; e a associação entre o declínio da mulher perante os interesses masculinos e o regime alimentício é realizado no próprio texto, quando admoesta: "Venderás o Secretario dos Amantes que te era auxiliar quando escrevias ás tuas namoradas, e comprarás o Cozinheiro Completo. Em vez de temperares phrases assucaradas, temperarás chocos de caldeirada" (ASSIS, 1869, p. 294-295). Ou seja: quando na relação predomina o interesse romântico, isso ocorre essencialmente pela capacidade da mulher de ostentar a "delicada cintura de vespa", preservando-se objeto do interesse masculino; se ela engorda, afastando-se do "typo ideal", assemelhando-se ao "prototypo da mulher do caseiro", o que resta é buscar à mesa um prazer que compense o outrora propiciado pelo amor; por conseguinte, a indisciplina da mulher acaba por contaminar toda a relação. Ao coração se sucede o estômago, consoante a fórmula camiliana - aliás, mencionada textualmente por José Bento d’Araujo Assis.

Naquela sociedade ordenada consoante estruturas patriarcais que confinava as mulheres ao espaço doméstico, encaminhando-as para cumprirem a missão de serem mães e esposas -, impunha-se, portanto, um dever às jovens que aspiravam a uma trajetória biográfica semelhante àquelas que estampavam as páginas da literatura romântica: serem como as donzelas que, em romances e poemas, apareciam como ideais de beleza, etéreas e espiritualizadas. O caminho para alcançar esse objetivo estava claramente traçado: importava não apenas cultivar a delicadeza e a fragilidade, mas também respeitar uma rígida dieta que construísse uma imagem corporal adequada - recorrendo ao vinagre e à privação alimentar, a fim de 
apresentar a magreza e a palidez necessárias. Examinada desde uma perspectiva feminista, a articulação de dispositivos de poder imediatamente salta à vista: numa sociedade em construção, o que poderia ser mais útil à preservação das estruturas de poder patriarcais do que uma geração de mulheres voluntariamente sujeitas a hábitos que as mantinham em condição subalterna e enfermiça?

\section{REFERÊNCIAS BIBLIOGRÁFICAS}

ASSIS, J. B. d'A.. Serões litterarios. Com duas cartas do exmo. sr. Camilo Castelo Branco. Lisboa: Typographia Universal de Thomaz Quintino Antunes, 1869.

BAPTISTA, A. B.. Futilidade da novela: a revolução romanesca de Camilo Castelo Branco. Campinas: Editora da Unicamp, 2012.

BELL, S.; OFFEN, K.. (eds.) Women, the family, and freedom: the debate in documents. v. I: 1750-1880. Stanford: Stanford University Press, 1983.

BORDO, S.. Unbearable weight: feminism, Western culture, and the body. Edição de décimo aniversário. Berkeley: Los Angeles: University of California Press, 2003.

BURTON, J. K.. Napoleon and the woman question: discourses of the Other Sex in French Education, Medicine, and Medical Law 1799-1815. Lubbock: Texas Tech University Press, 2007.

BRYSON, V.. Feminist Political Theory: an introduction. 2. ed. Nova Iorque: Palgrave Macmillan, 2003.

BYRNE, K.. Tuberculosis and the Victorian literary imagination. Nova Iorque: Cambridge University Press, 2011.

CABRAL, A.. Subsídio para uma interpretação da novelística camiliana. Lisboa: Livros Horizonte, 1985.

CASTELO BRANCO, Camilo. Scenas da Foz: solemnia verba: ultima palavra da sciencia. 2. ed. Porto: Cruz Coutinho - Editor, 1860.

. Coração, cabeça e estomago: romance. 2a. ed. Lisboa: A. M. Pereira, 1864.

CHERNOVIZ, P. L. N.. Diccionario de medicina popular. 2. ed. correcta e consideravelmente augmentada. v. III. Rio de Janeiro: Eduardo \& Henrique Laemmert, 1851.

CORVO, J. de A.. Pedro. (romance original). Caps. V e VI. O mosaico: jornal d'instrucção e recreio. Ano III, n. 94. 1841.

DESAN, S.. The French Revolution and the family. In: McPHEE, P. (ed.) A companion to the French Revolution. Malden: Blackwell, 2013. 
EMÍLIA. Archivo pittoresco. Semanario illustrado. Ano III. 1860.

ESTATUTOS da Sociedade do Giro dos Vinagres do Alto Douro. Porto: Typografia à praça de s. Thereza, 1822.

FERREIRA, A.. Perspectiva do romantismo português. Lisboa: Edições 70, 1971.

GREEN, J.. Public/private. In: CODE, L. (ed.). Encyclopedia of feminist theories. Nova Iorque: Routledge, 2000.

MARAND-FOUQUET, C.. A mulher no tempo da Revolução. Trad. Maria Mello. Mem Martins: Editorial Inquérito, 1993.

MENDONÇA, A. P. L.. de. O ultimo amor. Cap. II. Revista universal lisbonense. 2. série. Ano VIII, n. 43. 1849.

MICHAUD, S.. A mulher. In: FURET, F. (dir.) O homem romântico. Trad. Miguel Serras Pereira. Lisboa: Presença, 1999.

NOVAES, F. X. de. À sua primeira actriz. In: A Grinalda, periodico de poesias ineditas. Ano V. Porto: Typographia Commercial, 1864.

ORBACH, S.. Gordura é uma questão feminista. Trad. Cinthia Barki. Rio de Janeiro: Record, 1978.

PINTO, J. F. de M.. Toxicologia judicial e legislativa. Primeira e segunda parte: toxicologia geral e especial. Coimbra: Imprensa da Universidade, 1860.

ROLLAND, F. Adagios, proverbios, rifãos e anexins da lingua portugueza, tirados dos melhores autores nacionaes, e recopilados por ordem alfabetica. Nova edição correcta, e augmentada. Lisboa: Typographia Rollandiana, 1841.

SILVER, A. K.. Victorian Literature and the anorexic body. Cambridge: Cambridge University Press, 2002.

WOLF, N.. The beauty myth: how images of beauty are used against women. Nova Iorque: HarperCollins, 2002.

VAQUINHAS, I.. "Miserável e gloriosa": a imagem ambivalente da mulher no século XIX. In: "Senhoras e mulheres" na sociedade portuguesa do século XIX. Lisboa: Edições Colibri, 2000.

Recebido para publicação em 13/11/2013

Aprovado em 25/01/2014

\section{NOTAS}

1 "For if, whatever the specific historical content of the duality, the body is the negative term, and if woman is the body, then women are that negativity, whatever it may be: distraction from knowledge, seduction away from God, capitulation to sexual desire, violence or aggression, failure of will, even death." 